\title{
Corrosion by Polyaniline/Salicylaldehyde Modified Chitosan in Hydrochloric Acid Solution
}

\author{
Peipei Kong ${ }^{1,2, *}$, Nali Chen ${ }^{1,2}$, Yong Lu ${ }^{1,2}$, Huixia Feng ${ }^{1,2, *}$, Jianhui Qiu ${ }^{3}$ \\ ${ }^{1}$ College of Petrochemical Technology, Lanzhou University of Technology, Lanzhou 730050, China; \\ ${ }^{2}$ State Key Laboratory of Advanced Processing and Recycling of Nonferrous Metals, Lanzhou \\ University of Technology, Lanzhou 730050, China; \\ ${ }^{3}$ Department of Machine Intelligence and Systems Engineering, Faculty of Systems Engineering, \\ Akita Prefectural University, Akita, 015-0055, Japan \\ *E-mail: dongnan k@,163.com; fenghx66@163.com
}

doi: $10.20964 / 2019.10 .11$

Received: 20 May 2019 / Accepted: 24 July 2019 / Published: 30 August 2019

\begin{abstract}
A new type of natural polymer corrosion inhibitor, polyaniline/salicylaldehyde modified chitosan, was synthesized by an innovative method. The inhibition efficiency of polyaniline/salicylaldehyde modified chitosan was evaluated by electrochemical techniques. Surface analysis using SEM characterization were carried out to understand the corrosion inhibition property. Quantum chemical descriptors were investigated to explain the performance of polyaniline/salicylaldehyde modified chitosan as corrosion inhibitor. Experimental results show that the polyaniline/salicylaldehyde modified chitosan had better acid resistance. The quantum chemical study gives insight into the benefits of the corrosion mechanism of polyaniline/salicylaldehyde modified chitosan. It is envisioned that the inhibitor can be used to tailor the properties of the corrosion system for specific applications, resulting in more reliable and durable metal protection in the future.
\end{abstract}

Keywords: Chitosan; Polyaniline; Corrosion; Inhibition; Quantum chemical

\section{FULL TEXT}

(C) 2019 The Authors. Published by ESG (www.electrochemsci.org). This article is an open access article distributed under the terms and conditions of the Creative Commons Attribution license (http://creativecommons.org/licenses/by/4.0/). 